\title{
Psychopathology in people with epilepsy and intellectual disability; an investigation of potential explanatory variables
}

\author{
C A Espie, J Watkins, L Curtice, A Espie, R Duncan, J A Ryan, M J Brodie, K Mantala, M Sterrick
}

See Editorial Commentary p 1464

J Neurol Neurosurg Psychiatry 2003;74:1485-1492

See end of article for authors' affiliations

....................

Correspondence to: Professor C A Espie, University of Glasgow, Department of Psychological Medicine, Academic Centre, Gartnavel Royal Hospital, 1055 Great Western Road, Glasgow G12 OXH, UK; c.espie@clinmed. gla.ac.uk
Objectives: There are few studies on epilepsy and psychopathology in people with intellectual disability (mental retardation) despite epilepsy prevalence rates that are thirty times higher than in the general population. The aims of this study, therefore, were to identify reliable, epilepsy-specific predictors of psychiatric and behavioural disorder in these patients, and to investigate reliable predictors of carer stress. Methods: A database of 685 patients was compiled, from which 250 were randomly selected. Structured interviews were completed on 186 of these 250 patients (74\%) (108 men, 78 women; mean age (SD) 35.5 (10.1)) comprising descriptive, clinical and functional components, and validated measures of psychopathology for which comparative data were available. Logistic and linear regression methods were used to identify predictors.

Results: One-third of patients with epilepsy and intellectual disability met criteria for possible psychiatric disorder, particularly affective/neurotic disorder; twice the comparison rates for intellectual disability alone. Behavioural problem levels, however, were lower than population norms. Regression models explaining modest amounts of variance $\left(R^{2} \leqslant 24 \%\right)$ suggested certain seizure phenomena (greater seizure severity, more seizures in past month, lesser tendency to loss of consciousness during seizures) as particular risk factors for psychiatric disorder. General disability factors such as level of intellectual, sensory or motor disability and side effects of medication, however, contributed more to explaining behavioural problems. Around half of the family carers reported significant stress, and one-third exhibited clinically significant anxiety symptoms. Younger carers were more stressed, and side effects from patients' medication also contributed to carer stress.

Conclusions: Although epilepsy in itself may be a risk factor for psychopathology in a minority of people with intellectual disability, some epilepsy-specific factors may predict psychiatric disorder. Behavioural problems need to be considered separately from psychiatric disorder because general factors, more closely associated with disability, are stronger predictors of their occurrence.
E pilepsy is the most common serious neurological disorder affecting people with intellectual disabilities (mental retardation) with prevalence ranging from 20$40 \%{ }^{1-3} 30$ times higher than the general population rate. ${ }^{45}$ Three-quarters of the latter become seizure free on antiepileptic drug (AED) therapy. ${ }^{6}$ Epilepsy in people with intellectual disabilities is more difficult to manage, although clinical guidelines have recently been developed by a working group of the International Association for the Scientific Study of Intellectual Disability. ${ }^{7}$ Chronic epilepsy may also be associated with psychiatric, behavioural and socioeconomic sequelae,,$^{8-10}$ and with increased risk of hospitalisation and failures of community care. ${ }^{11}$ It is particularly important, therefore, to understand the functional and behavioural consequences of epilepsy in this population..$^{72}$

However, only five cohorts of adults with epilepsy and intellectual disability have been studied in comparison with non-epileptic controls. The first two studies, conducted in Glasgow, were a matched pair comparison study of residential patients with and without epilepsy (total $\mathrm{n}=30$; mean age 28 years), ${ }^{13}$ and a larger scale controlled study in the community $(\mathrm{n}=130$; mean age 30 years $) ..^{14} \mathrm{~A}$ third controlled study (Leicester, UK) comprised both hospital and community participants, and was published as a series of papers $(n=300$; mean age 40 years $) .{ }^{16-18}$ The fourth study was from Louisiana, USA, and presented comparative survey data from within a large residential developmental centre ( $\mathrm{n}=706$; mean age 40 years $),{ }^{19}$ and the fifth and most recent study (Coventry, UK) used a small residential sample $(\mathrm{n}=28$; mean age 35 years $) .^{20}$ To summarise these reports, no compelling evidence of epilepsy related psychopathology (either psychiatric disorder or challenging behaviour disorder) has emerged from intergroup comparison, although there may be a sub-group of people with epilepsy and intellectual disability 'at risk' of psychopathology, that is, those with frequent seizures and/or those on AED polytherapy.

It seems important to investigate such risk factors further. Therefore, we adopted an intragroup correlational design, using multivariate regression models, with the primary aim of establishing reliable predictors (epilepsy related or other) of such comorbidity in a sizeable, randomly selected adult sample. Our secondary aim was to investigate the impact of epilepsy upon family carers, and to identify any epilepsy specific predictors of carer stress or psychopathology.

Abbreviations: $A B C$, Aberrant Behaviour Checklist; $A E D$, anti-epileptic drug; CSI, Caregiver Strain Index; ELDQOL, Epilepsy and Learning Disabilities Quality of Life scale; HADS, Hospital Anxiety and Depression Scale; PAS-ADD, Psychiatric Assessment Schedule for Adults with Developmental Disabilities V-ABS, Vineland Adaptive Behaviour Scales 


\section{METHODS}

\section{Participants}

A database was compiled on 685 adults with epilepsy and intellectual disability. Clinical sources were hospital based epilepsy clinics and community learning disability teams in Glasgow, and specialist clinics for epilepsy plus intellectual disability in Edinburgh. Inclusion criteria were: (a) adults 18-60 years; $(b)$ at least mild mental retardation according to World Health Organisation (ICD-10) definitions (incomplete or arrested development of the mind, with diminished ability to adapt to the social environment, and IQ $\leqslant 69)$; (c) epilepsy confirmed by clinical history; $(d)$ having at least one seizure per month on average; and (e) a carer (family and/or staff) who had participated in care decisions for at least the preceding 3 months. Exclusions were deteriorating health, particularly neurological disorders, and non-epileptic seizure disorders.

We used our database to select 250 potential participants using random number sequences generated by SPSS (v. 9.0; SPSS Inc., Chicago, IL, USA). Of these, seven carers refused participation, and attempts to contact 54 were unsuccessful. Therefore, agreement was reached for 189 participants; however, three were excluded due to age $(n=2)$ and nonepileptic seizures $(n=1)$. From the remaining $186(74 \%$ of our random sample), 76 lived with relatives (41\%), 84 (45\%) lived in the community with staff carers, and 26 (14\%) lived in an institutional setting. One hundred and eighteen (63\%) lived in Glasgow, and 68 (37\%) in Edinburgh. As anticipated, there were more males $(\mathrm{n}=108 ; 58 \%)$ than females $(\mathrm{n}=78$; $42 \%$ ). Mean age was 39 years in staffed environments, significantly older than the mean of 31 years in clients who lived with family (mean difference 7.69 years, 95\% CI 4.45 to 10.9). Our sample of 186 did not differ from the total database group in gender, age, recruitment site, degree of disability, or seizure frequency (all $\mathrm{p}>0.05$ ) and, therefore, may be regarded as representative of this selected population. A sample greater than $n \geqslant 125$ should detect medium effect sizes in the association between variables with power at 0.8 , $\mathrm{p}<0.01$. $^{21}$

All participants were rated as having a deficit in daily living skills on the Vineland Adaptive Behaviour Scales ${ }^{22}$ (V-ABS), with $14(8 \%)$ exhibiting borderline, 20 (11\%) mild, eight (4\%) moderate, $15(8 \%)$ severe, and 128 (69\%) profound deficit. Level of intellectual disability was estimated from these V-ABS functional ability profiles, combined with available clinical or psychometric reports. Three-quarters $(\mathrm{n}=139)$ had at least moderate intellectual disability (IQ range 35-40 to 50-55), of whom 27 (15\%) were profoundly disabled (IQ level below 20-25). No significant difference was found between those living at home and those in care. One quarter $(\mathrm{n}=47)$ was non-ambulant, $27(15 \%)$ had hearing impairment, $62(33 \%)$ visual impairment and 55 $(30 \%)$ had no speech. The principal carer was a family member for 78 individuals and a staff carer for 108 individuals. Mean age of family carers was 57 years compared to 37 years in staff carers (mean difference 19.4 years, $95 \%$ CI 16.0 to 22.8 years), and family carers had cared for the person for significantly longer (mean of 28.7 years compared with 5.8 years).

Epilepsy was most often managed by an epilepsy specialist/ consultant neurologist $(68 \%)$ and/or a general medical practitioner $(49 \%)$. In many cases $(n=78,42 \%)$ both the neurologist and GP were involved. In 14 cases (8\%), epilepsy was not currently managed by any clinician. Polypharmacy was common: 62 patients (33\%) were prescribed two AEDs, $58(31 \%)$ three AEDs and 16 (9\%) four or more AEDs. Fifty patients were on AED monotherapy (27\%). Mean age at onset of epilepsy was 4.5 years, ranging from birth to 38 years. Forty $(22 \%)$ had seizures at least daily, $63(35 \%)$ at least weekly, $56(31 \%)$ at least monthly and $22(12 \%)$ less frequently $(\mathrm{n}=181$; five missing cases).

Descriptions of seizure presentations, obtained from the principal carer, were rated blind by an experienced epileptologist to obtain an assessment of likely seizure types $(n=182$ available). The majority of patients had more than one seizure type $(52 \%)$. Most common were tonic-clonic $(61 \%)$ and complex partial seizures $(44 \%)$, with myoclonic and absence seizures each at $10 \%$. Forty-four participants $(24 \%)$ had some seizures coded as unclassifiable.

\section{Measures and procedure}

A structured interview was completed with the principal carer using measures of functional independence (V-ABS) and epilepsy-related quality of life (Epilepsy and Learning Disabilities Quality of Life scale ${ }^{23}$; ELDQOL). Seizure diaries were used to corroborate estimates of seizure frequency, ${ }^{24}$ and ELDQOL sub-scales were calculated for seizure severity and drug side effects. The latter was adapted by excluding items on mood or behavioural disturbance, and summing scores on unsteadiness, tiredness, headache, hair loss, skin problems such as rash, blurred or double vision, weight gain, dizziness, sleepiness, and problems affecting memory, concentration, the gastrointestinal tract, and the mouth/gums. Other interview questions covered aetiological factors and presence or absence of significant visual impairment, hearing impairment, functional speech, and ambulation.

There is no "gold standard" measure of psychiatric disorder for the intellectually disabled population. However, the Psychiatric Assessment Schedule for Adults with Developmental Disabilities ${ }^{25}$ (PAS-ADD) utilises ICD-10 criteria. We selected the PAS-ADD Checklist ${ }^{26}$ because it is validated as a screening tool for use in structured interviews with carers. It yields three threshold scores that reliably identify possible psychiatric disorder, that is, affective or neurotic disorder, organic condition, and psychotic disorder. We also wished to assess behavioural dimensions. We selected the Aberrant Behaviour Checklist ${ }^{27}$ (ABC) because it has been extensively validated, normative data are available, ${ }^{28}$ and it has been recommended for use with people with epilepsy. ${ }^{29}$ Sub-scale structure (I: irritability/agitation, II: lethargy/social withdrawal, III: stereotypic behaviour, IV: hyperactivity/non-compliance, V: inappropriate speech) has been replicated in a UK population. ${ }^{30}$ The ABC has a total of 58 items, each on a four-point Likert Scale.

Finally, we wished to assess carer coping amongst the family carer group $(n=78)$. These informants completed the Hospital Anxiety and Depression Scale ${ }^{31}$ (HADS), a 14-item measure of symptoms of anxiety and depression that has satisfactory reliability $(\mathrm{r}=0.70$ for anxiety; $\mathrm{r}=0.74$ for depression), and the Caregiver Strain Index ${ }^{32}$ (CSI). The CSI was originally developed for use with carers of older adults with dementia, but with minor adaptations, we considered that its content was suitable for the assessment of the strain associated with the burden of caring for this population.

\section{Statistical analyses}

Descriptive data are presented as mean scores with standard deviations (SD) or as percentages. Parametric statistics were used for difference testing and correlation where underlying assumptions were met, otherwise non-parametric equivalents were applied. To select variables for inclusion in regression models, we conducted a series of bivariate analyses to identify a subset that might depart from a chance relationship with the outcome variable in question. To ensure inclusion of all such variables, alpha was set at $\mathrm{p}<0.10$ to avoid type II error. ${ }^{34}$ Logistic and linear regression models were explored for categorical and continuous dependent variables respectively. 
Table 1 Psychiatric classification using the PAS-ADD checklist

\begin{tabular}{|c|c|c|c|c|c|c|}
\hline \multirow[b]{2}{*}{ PAS-ADD Checklist } & \multicolumn{2}{|l|}{ This sample* } & \multicolumn{2}{|c|}{ Comparison sample I† } & \multicolumn{2}{|c|}{ Comparison sample $\|^{* *}$} \\
\hline & Non-cases n (\%) & Cases n (\%) & Non-cases n (\%) & Cases n (\%) & Non-cases n (\%) & Cases n (\%) \\
\hline $\begin{array}{l}\text { Score 1: possible affective or neurotic } \\
\text { disorder }\end{array}$ & $130(71.4)$ & $52(28.6)$ & $\begin{array}{r}157(88.2) \ddagger \\
125(89.9) \S \\
32(82.0) \uparrow\end{array}$ & $\begin{array}{r}21(11.8) \ddagger \\
14(10.1) \S \\
7(18.0)\end{array}$ & 103 (81.1)‡ & $24(18.9) \ddagger$ \\
\hline Score 2: possible organic condition & $169(92.9)$ & $13(7.1)$ & $\begin{array}{r}171(96.1) \ddagger \\
133(95.7) \S \\
38(97.4)\end{array}$ & $\begin{array}{l}7(3.9) \ddagger \\
6(4.3) \S \\
1(2.6) \uparrow\end{array}$ & 122 (96.0)‡ & $5(4.0) \neq$ \\
\hline Score 3: possible psychotic disorder & $163(89.6)$ & $19(10.4)$ & $\begin{array}{r}156(87.6) \ddagger \\
122(87.8) \S \\
34(87.2)\end{array}$ & $\begin{array}{r}22(12.4) \ddagger \\
17(12.2) \S \\
5(12.8)\end{array}$ & $97(76.4) \ddagger$ & $30(23.6) \ddagger$ \\
\hline $\begin{array}{l}\text { Merged score: at least one possible } \\
\text { disorder }\end{array}$ & $122(67.0)$ & $60(33.0)$ & $\begin{array}{r}145(81.5) \ddagger \\
117(84.2) \S \\
28(71.8)\end{array}$ & $\begin{array}{l}33(18.5) \ddagger \\
22(15.8) \S \\
11(28.2)\end{array}$ & $85(67.0) \ddagger$ & $42(33.0) \ddagger$ \\
\hline
\end{tabular}

${ }^{*} \mathrm{n}=182$ (four missing cases, Scottish sample of adults with epilepsy and intellectual disabilities); $\nmid n=178$ (community health survey sample of adults with intellectual disabilities; Moss, personal communication); łtotal community comparison sample; §comparison sample with no epilepsy; 9 comparison sample with epilepsy; ${ }^{* *} \mathrm{n}=127$ (Roy et al., 1997; community sample using intellectual disability services and on multiagency register ${ }^{33}$ )

\section{RESULTS}

\section{Comparative data on psychopathology}

Psychiatric Assessment Schedule for Adults with Developmental Disabilities

PAS-ADD data were available for 172 participants (92\%; Table 1). More than one-quarter scored at or above threshold for possible neurotic or affective disorder, with $7 \%$ and $10 \%$ respectively reaching thresholds for possible organic and psychotic disorders. One-third of participants rated at or above threshold for at least one classification. There are no published norms for the PAS-ADD Checklist. However, data were available from a community health survey in England (comparison sample I $(n=178)$; Moss, personal communication) and we extracted information from the only published report (comparison sample $\operatorname{II}^{33} \quad(\mathrm{n}=127)$ ). Sample I comprised a heterogeneous group of adults with intellectual disability (107 males, 71 females; median age 45 years, range $18-88$ years). Sample II comprised 81 males and 46 females in the age range $19-89$ years. ${ }^{33}$ These demographics are similar to our own.

Our sample presented more than double the rate of possible affective or neurotic disorder reported for comparison sample I and had a higher rate of possible organic disorder (table 1). Overall, one-third of our participants had possible psychiatric disorder compared with 19\% in sample I. However, when sample I was dichotomised into those with/ without epilepsy, $28 \%$ of the community subgroup with epilepsy had at least one possible disorder, a finding similar to our own. We advise caution in the interpretation of these data because sample I comprises unpublished data, the validity of which cannot be readily established. Comparison sample II had an identical rate of possible psychiatric disorder $(33 \%)$; however, a higher rate of psychotic symptoms and a lower rate of affective symptoms was reported. This may reflect the sample characteristics from Roy et al, ${ }^{33}$ because all subjects were registered as requiring some form of specialised health service on a multiagency register. Of course, data from all three sources (sample I and II, and our own sample) are influenced by sampling factors.

\section{Aberrant Behaviour Checklist}

To evaluate internal consistency for the ABC sub-scales, Cronbach's $\alpha$ was calculated (table 2 ). In all cases $\alpha$ was greater than 0.80 , and the reliability profile was similar to a published analysis. ${ }^{27}$ Table 2 presents mean (SD) data for each subscale compared with standardisation data ${ }^{28}$ $(\mathrm{n}=1022)$. The profile of our sample appears similar to the standardisation sample, but our mean scores were consistently lower. For example, irritability and hyperactivity obtained the highest values in both samples but our participants scored around 4 points lower (equivalent to $0.5 \mathrm{SD}$ ). Further comparison with supplementary norms ${ }^{28}$ indicated that our sample consistently lay below the 50th centile on each subscale.

\section{Inter-relationship between measures of psychopathology}

The sample was dichotomised on the PAS-ADD variable "at least one possible psychiatric disorder/no psychiatric disorder", and a comparative analysis of ABC scores was conducted (table 3). Participants with possible psychiatric disorder had higher scores on three domains (Irritability, Hyperactivity, Inappropriate Speech), suggesting that psychiatric status and behaviour disturbance are not independent of one another. Nevertheless, mean scores associated with possible psychiatric disorder remained lower than standardisation population means (table 2). A correlation matrix of $\mathrm{ABC}$ sub-scale scores demonstrated modest to strong association between behavioural measures (range of $\mathrm{r}=0.250 \quad($ Lethargy $\times$ Inappropriate Speech) to $\mathrm{r}=0.755$ (Irritability $\times$ Hyperactivity); all $\mathrm{p}<0.001)$ ).

\section{Predictors of psychopathology}

Our primary interest was to identify specific predictors of psychopathology. We explored all available demographic and clinical variables, and summary data (table 4 ) indicate that a range of functional, clinical, and epilepsy related variables was identified, which met our initial criteria for entry in regression analyses.

Six separate regression analyses were conducted; one logistic (PAS-ADD) and five linear (ABC sub-scales). A first series specifically included, as potential explanatory variables, those other measures of psychopathology that met our threshold criterion. This was because we recognised the overlap/redundancy in measurement of what might be similar psychopathological phenomena. A second series was conducted, after exclusion of these variables, to identify different types of predictors, the effect of which may have been masked by intercorrelation among measures of psychopathology. The latter series evaluates how clinical disorder/ patient characteristics may predict mood and behaviour.

\section{Psychiatric Assessment Schedule for Adults with} Developmental Disabilities

Forwards stepwise logistic regression on the PAS-ADD variable yielded a significant model $\left(\chi^{2}=38.74, \mathrm{df}=4\right.$, $\mathrm{p}<0.0001$ ), correctly classifying $86.7 \%$ of non-cases and $46.3 \%$ of cases (overall $72.4 \%$ ). This comprised four significant predictors; greater $\mathrm{ABC}$ hyperactivity $(\mathrm{OR}=1.126$, 
Table 2 Internal consistency and performance data on the sub-scales of the Aberrant Behaviour Checklist

\begin{tabular}{llllc}
\hline $\begin{array}{l}\text { Aberrant Behaviour Checklist } \\
\text { sub-scales }\end{array}$ & $\begin{array}{l}\text { This sample* } \\
\text { Cronbach } \alpha\end{array}$ & $\begin{array}{l}\text { Derivation } \\
\text { sample† } \\
\text { Cronbach } \boldsymbol{\alpha}\end{array}$ & $\begin{array}{l}\text { This sample* } \\
\text { Mean (SD) }\end{array}$ & $\begin{array}{l}\text { Normative datat } \\
\text { Mean (SD) }\end{array}$ \\
\hline Irritability (13 items) & 0.90 & 0.92 & $6.54(7.60)$ & $10.54(9.80)$ \\
Lethargy (16 items) & 0.90 & 0.91 & $4.85(6.77)$ & $8.42(8.88)$ \\
Stereotypic behaviour (7 items) & 0.87 & 0.90 & $1.34(2.79)$ & $3.61(4.74)$ \\
Hyperactivity (16 items) & 0.86 & 0.94 & $5.91(7.32)$ & $10.37(10.26)$ \\
Inappropriate speech (4 items) & 0.80 & 0.86 & $1.26(2.19)$ & $1.90(2.81)$ \\
\hline
\end{tabular}

${ }^{*} n=178$ (eight missing cases, Scottish sample of adults with epilepsy and intellectual disabilities); $\uparrow n=1022$ (Aberrant Behaviour Checklist-Community supplementary manual: combined adult data ${ }^{28}$ )

95\% CI 1.063 to $1.193, \mathrm{p}<0.001)$, more seizures in the past month $(\mathrm{OR}=1.012$, 95\% CI 0.999 to $1.024, \mathrm{p}=0.072)$, greater seizure severity ( $\mathrm{OR}=0.53395 \%$ CI 0.348 to 0.818 , $\mathrm{p}=0.004)$ and less frequent loss of consciousness during seizures $(\mathrm{OR}=3.18,95 \% \mathrm{CI} 1.33$ to $7.62, \mathrm{p}=0.009)$. The second analysis $\left(\chi^{2}=22.1, \mathrm{df}=3, \mathrm{p}<0.0001\right)$, excluding $\mathrm{ABC}$ data, retained seizures in the past month $(\mathrm{OR}=1.017,95 \% \mathrm{CI}$ 1.004 to $1.030, p=0.012$ ), seizure severity ( $O R=1.098,95 \%$ CI 1.036 to $1.165, p=0.002$ ), and loss of consciousness (OR $=0.265,95 \%$ CI 0.105 to $0.669, \mathrm{p}=0.005)$, but identified fewer PAS-ADD cases (90.7\% of non-cases, $25.9 \%$ of cases; overall $67.5 \%$ ).

\section{Aberrant Behaviour Checklist}

The results of stepwise linear regression analyses are presented in table 5 . Series 1 analyses explained variance $\left(\mathrm{R}^{2}\right)$ in the range $24-53 \%$, with irritability and hyperactivity demonstrating marked interaction. Only the prediction of lethargy and stereotypic behaviour introduced other types of explanatory variables. For the former, speech impairment, intellectual impairment and drug side effects contributed, and, as can be seen in series 2, these explained $24 \%$ of variance in lethargy scores. A significant interaction between intellectual and speech impairment was observed $\left(\chi^{2}=50.06\right.$, $\mathrm{df}=1, \mathrm{p}<0.001)$. For stereotypic behaviour, intellectual impairment contributed modestly, and in series 2 , together with visual impairment, $8 \%$ of variance was explained. The exclusion of behavioural and mood measures also permitted the emergence of drug side effects as an explanatory factor in both inappropriate speech and irritability, again with modest effect, and being ambulant emerged as a contributory predictor of hyperactivity, irritability, and inappropriate speech. Table 5 describes those specific side effects that contributed most strongly to the predictive models concerned. It should be noted that, with the exception of ABC lethargy, explained variance associated with series 2 was considerably lower than series 1 .

\section{Descriptive data on family carer coping}

Hospital Anxiety and Depression Scale and Caregiver Strain Index

Mean scores for the anxiety and depression sub-scales of the HADS were 8.33 (4.61) and 5.06 (4.47) respectively (both $\mathrm{n}=72$; six missing cases). Using the conservative cut-off of 11 or greater, 24 carers $(33.3 \%)$ had a clinically significant level of anxiety symptoms and eight $(11.1 \%)$ had clinically significant depressive symptoms. HADS anxiety and depression scales correlated at $\mathrm{r}=0.602$ in our sample. The CSI has not previously been used with carers of people with intellectual disabilities. Reliability coefficients, therefore, were calculated and Cronbach's $\alpha$ was found to be 0.80 , indicating acceptable internal consistency. Mean (SD) value on the CSI was 6.03 (3.60) and 43 of the 72 carers (53.1\%) had 'higher than usual stress'. HADS anxiety and HADS depression sub-scales correlated with CSI $(r=0.531$ and 0.416 respectively), suggesting that the HADS and CSI have at least $70 \%$ unshared variance. Half of the carers with higher than usual stress on the CSI were "cases" according to HADS anxiety scores, whereas $71 \%$ of "case" on the HADS anxiety subscale had higher than usual stress. This suggests that the HADS is a more conservative measure than the CSI.

\section{Predictors of family coping}

Eight variables emerged from bivariate analysis $(p<0.10$; see above) as potential predictors using the dichotomised HADS anxiety data (possible case/not case). These were patient hyperactivity $(\mathrm{p}=0.004)$, seizure severity $(0.012)$, irritability (0.014), inappropriate speech (0.021), use of rectal diazepam $(0.044)$, number of acute episodes in past year $(0.052)$, PASADD caseness (0.069), and loss of consciousness during seizures $(0.080)$. Logistic regression, however, revealed only one significant predictor. Seizure severity (less severe) was associated $(\mathrm{OR}=1.094,95 \% \mathrm{CI} 1.015$ to 1.179$) ; \mathrm{p}=0.019)$ with correct classification of non-cases of HADS anxiety $(89.5 \%)$ but was a relatively poor predictor of cases $(31.6 \%)$ $\left(\chi^{2}=6.52, \mathrm{df}=1, \mathrm{p}=0.011\right)$. Likewise, eight variables were

Table 3 Differences between PAS-ADD identified "cases" and "non-cases" on subscales of the Aberrant Behaviour Checklist

\begin{tabular}{|c|c|c|c|c|c|c|}
\hline & $\begin{array}{l}\text { Caseness on PAS-ADD: at least } \\
\text { one dimension }\end{array}$ & $\mathbf{n}$ & Mean (SD) & $t$ & df & $\begin{array}{l}\text { Significance } \\
\text { (two-tailed) }\end{array}$ \\
\hline$A B C$ irritability & $\begin{array}{l}\text { Not case } \\
\text { Possible case }\end{array}$ & $\begin{array}{r}117 \\
60\end{array}$ & $\begin{array}{l}4.92(6.52) \\
9.77(8.60)\end{array}$ & -4.18 & 175 & $<0.001$ \\
\hline$A B C$ lethargy & $\begin{array}{l}\text { Not case } \\
\text { Possible case }\end{array}$ & $\begin{array}{r}117 \\
60\end{array}$ & $\begin{array}{l}4.16(6.41) \\
6.15(7.35)\end{array}$ & -1.85 & 175 & 0.065 \\
\hline$A B C$ stereotypic behaviour & $\begin{array}{l}\text { Not case } \\
\text { Possible case }\end{array}$ & $\begin{array}{r}117 \\
60\end{array}$ & $\begin{array}{l}1.13(2.35) \\
1.77(3.51)\end{array}$ & -1.43 & 175 & 0.152 \\
\hline$A B C$ hyperactivity & $\begin{array}{l}\text { Not case } \\
\text { Possible case }\end{array}$ & $\begin{array}{r}117 \\
60\end{array}$ & $\begin{array}{l}4.13(9.38) \\
9.38(9.02)\end{array}$ & -4.77 & 175 & $<0.001$ \\
\hline$A B C$ inappropriate speech & $\begin{array}{l}\text { Not case } \\
\text { Possible case }\end{array}$ & $\begin{array}{r}117 \\
60\end{array}$ & $\begin{array}{l}0.99(1.88) \\
1.77(2.65)\end{array}$ & -2.24 & 175 & 0.026 \\
\hline
\end{tabular}

( $n=177$; nine missing cases); df, degrees of freedom. 
Table 4 Variables entered in regression models having demonstrated significant association with variable to be predicted

\begin{tabular}{|c|c|c|c|}
\hline Variable & Analysis & Variable & Analysis \\
\hline PAS-ADD (case/not case) & & $A B C$ irritability & \\
\hline$A B C$ irritability & 9.76 (8.59) v $4.92(6.52) ; p<0.001$ & $A B C$ hyperactivity & $r=0.755 ; p<0.001$ \\
\hline$A B C$ hyperactivity & $9.38(9.01) \vee 4.12(5.56) ; p<0.001$ & $A B C$ stereotypy & $r=0.499 ; p<0.001$ \\
\hline Seizure rate past 1 month & Mdn $10 \vee 5 ; p=0.009$ & PAS-ADD case (yes/no) & $\begin{array}{l}9.77(8.60) \text { v } 4.92(6.52) ; \\
p<0.001\end{array}$ \\
\hline Seizures past 12 month & Mdn 96 v 60; $p=0.017$ & $A B C$ inappropriate speech & $r=0.474 ; p<0.001$ \\
\hline$A B C$ inappropriate speech & $1.77(2.65) \vee 0.99(1.88) ; p=0.026$ & $A B C$ lethargy & $r=0.360 ; p<0.001$ \\
\hline $\begin{array}{l}\text { Loses consciousness in } \\
\text { seizure (yes/no) }\end{array}$ & $\chi^{2}(1)=2.96 ; p=0.061$ & Drug side effects (ELDQOL) & rho $=0.321 ; p<0.001$ \\
\hline$A B C$ lethargy & $6.15(7.34) \vee 4.16(6.41) ; p=0.065$ & Visual impairment (yes/no) & $\begin{array}{l}8.35(8.64) \text { v } 5.48(6.68) ; \\
p=0.016\end{array}$ \\
\hline $\begin{array}{l}\text { Aetiology (brain damage/ } \\
\text { infection = risk) }\end{array}$ & $\chi^{2}(1)=2.80 ; p=0.067$ & Ambulant (yes/no) & $\begin{array}{l}7.00(7.28) \text { v } 4.32(6.55) ; \\
p=0.035\end{array}$ \\
\hline Seizure severity (ELDQOL) & $31.1(8.35) \vee 28.7(7.68) ; p=0.068$ & Seizure severity (ELDQOL) & rho $=0.152 ; p=0.052$ \\
\hline Age & $33.5(10.1) \vee 36.3(12.0) ; p=0.085$ & & \\
\hline$A B C$ stereotypic behaviour & & $A B C$ hyperactivity & \\
\hline$A B C$ hyperactivity & $r=0.548 ; p<0.001$ & $A B C$ irritability & $r=0.755 ; p<0.001$ \\
\hline$A B C$ lethargy & $r=0.502 ; p<0.001$ & $A B C$ stereotypy & $r=0.548 ; p<0.001$ \\
\hline$A B C$ irritability & $r=0.499 ; p<0.001$ & $A B C$ inappropriate speech & $r=0.540 ; p<0.001$ \\
\hline$A B C$ inappropriate speech & $r=0.368 ; p<0.001$ & PAS-ADD case (yes/no) & $\begin{array}{l}9.38(9.02) \text { v } 4.13(5.57) ; \\
p<0.001\end{array}$ \\
\hline $\begin{array}{l}\text { Intellectual impairment } \\
(\geqslant \text { severe } / \leqslant \text { moderate })\end{array}$ & $2.04(3.67) \vee 0.84(1.68) ; p=0.006$ & Drug side effects (ELDQOL) & rho $=0.372 ; p<0.001$ \\
\hline Community skills (V-ABS) & rho $=-0.201 ; p=0.007$ & $A B C$ lethargy & $r=0.382 ; p<0.001$ \\
\hline Personal skills (V-ABS) & rho $=-0.186 ; p=0.013$ & Ambulant (yes/no) & $\begin{array}{l}6.82(7.63) \vee 2.69(4.28) ; \\
p=0.001\end{array}$ \\
\hline Acute episodes past & rho $=-0.171 ; p=0.023$ & Seizure severity (ELDQOL) & rho $=0.203 ; p=0.010$ \\
\hline $\begin{array}{l}12 \text { months } \\
\text { Domestic skills (V-ABS) }\end{array}$ & rho $=-0.147 ; p=0.049$ & & \\
\hline Speech impairment (yes/no) & $0.91(1.92) \vee 1.84(3.34) ; p=0.024$ & & \\
\hline Male/ female & $1.71(3.35) \vee 0.84(1.63) ; p=0.038$ & & \\
\hline Rectal diazepam (yes/no) & $1.60(3.11) \vee 0.85(1.78) ; p=0.057$ & & \\
\hline Visual impairment (yes/no) & $1.80(3.11) \vee 1.02(2.42) ; p=0.068$ & & \\
\hline Seizure rate past 1 month & rho $=-0.133 ; p=0.081$ & & \\
\hline Seizures past 12 month & rho $=-0.127 ; p=0.095$ & & \\
\hline$A B C$ lethargy & & $A B C$ inappropriate speech & \\
\hline ABC stereotypy & $r=0.502 ; p<0.001$ & $A B C$ hyperactivity & $r=0.540 ; p<0.001$ \\
\hline$A B C$ hyperactivity & $r=0.382 ; p<0.001$ & $A B C$ irritability & $r=0.474 ; p<0.001$ \\
\hline$A B C$ irritability & $r=0.360 ; p<0.001$ & $A B C$ stereotypy & $r=0.368 ; p<0.001$ \\
\hline Community skills (V-ABS) & rho $=-0.307 ; p<0.001$ & $A B C$ lethargy & $r=0.250 ; p=0.001$ \\
\hline$A B C$ inappropriate speech & $r=0.250 ; p=0.001$ & Speech impairment (yes/no) & $\begin{array}{l}0.56(1.35) \text { v } 1.58(7.32) \\
p=0.003\end{array}$ \\
\hline $\begin{array}{l}\text { Intellectual impairment } \\
(\geqslant \text { severe } / \leqslant \text { moderate })\end{array}$ & $6.78(8.30) \vee 3.48(4.96) ; p=0.002$ & Drug side effects (ELDQOL) & rho $=0.246 ; p=0.004$ \\
\hline Personal skills (V-ABS) & rho $=-0.229 ; p=0.002$ & Seizure severity (ELDQOL) & rho $=0.212 ; p=0.007$ \\
\hline Drug side effects (ELDQOL) & rho $=0.247 ; p=0.004$ & Ambulant (yes/ no) & $\begin{array}{l}1.55(2.46) \vee 0.63(1.18) ; \\
p=0.019\end{array}$ \\
\hline Speech impairment (yes/no) & $3.36(4.80) \vee 6.19(7.43) ; p=0.004$ & PAS-ADD case (yes/no) & $\begin{array}{l}1.77(2.65) \vee 0.99(1.88) ; \\
p=0.026\end{array}$ \\
\hline Domestic skills (V-ABS) & rho $=-0.202 ; p=0.007$ & & \\
\hline Seizure severity (ELDQOL) & rho $=0.182 ; p=0.021$ & & \\
\hline PAS-ADD case (yes/no) & $6.15(7.34) \vee 4.16(6.41) ; p=0.065$ & & \\
\hline Hearing impairment (yes/no) & $6.33(8.83) \vee 4.06(5.80) ; p=0.091$ & & \\
\hline
\end{tabular}

identified to enter logistic regression upon HADS depression (irritability and hyperactivity (both $\mathrm{p}<0.01$ ), inappropriate speech (0.007), seizure severity (0.024), lethargy (0.078), rectal diazepam (0.083), drug side effects (0.092), and degree of intellectual impairment (0.093)); however, none reached criterion for acceptance in the regression equation.

Eight variables were entered into regression analysis of the categorised CSI variable; namely, carer age (higher stress in younger carers; $p=0.001)$, irritability $(0.005)$, hyperactivity (0.007), drug side effects (0.007), inappropriate speech (0.008), having myoclonic seizures (0.022), visual impairment $(0.031)$, and patient age (higher stress when patients younger; 0.041). A combination of carer age $(\mathrm{OR}=0.900$, $95 \%$ CI 0.829 to $0.972, p=0.010$ ) and side effects $(\mathrm{OR}=1.100,95 \%$ CI 1.018 to $1.188, \mathrm{p}=0.015)$ correctly allocated $81.5 \%$ of those with normal stress and $65.4 \%$ of those with higher than usual stress (overall 73.6\%) $\left(\chi^{2}=17.187, \mathrm{df}=2, \mathrm{p}=0.002\right)$.

\section{DISCUSSION}

We approached the possibility of association between epilepsy and psychopathology by comparing our sample with available data, and by investigating explanatory variables using regression modelling. To our knowledge, this latter methodology has not been applied previously. Furthermore, our sample $(\mathrm{n}=186)$ is large compared with the published literature, and was drawn at random from a large cohort $(\mathrm{n}=685)$.

\section{Psychiatric disorder}

Thirty-three percent satisfied one or more PAS-ADD threshold score, an overall rate of disorder identical to a previous 


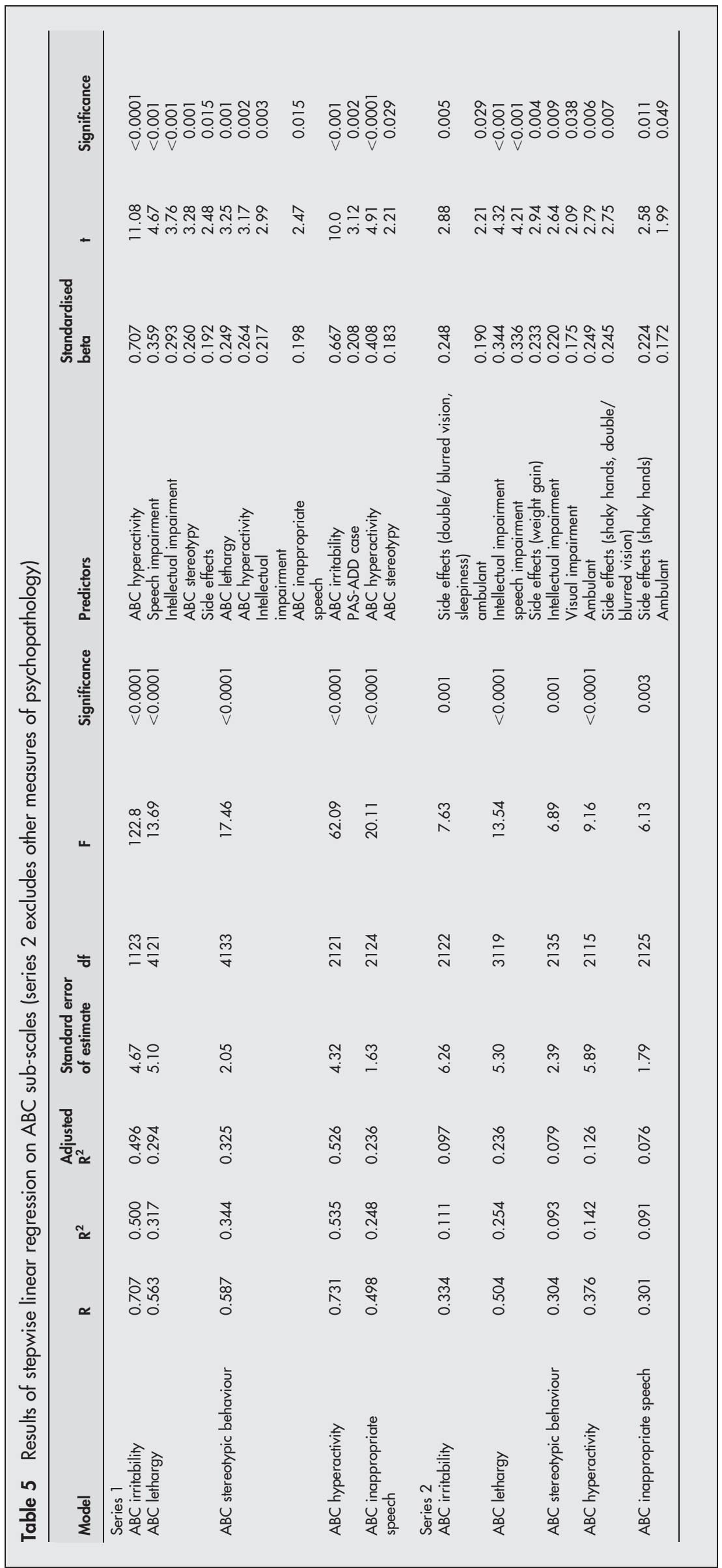


report on a heterogeneous sample, ${ }^{33}$ although other data have suggested lower community prevalence (19\%; Moss, personal communication). We found affective/neurotic disorder to be the most prevalent category $(29 \%)$ and we identified only 19 possible cases ( $10 \%)$ of psychotic disorder. Interestingly, Roy et al reported more psychotic than neurotic disorder. ${ }^{33}$ These differences probably reflect sampling characteristics. We suggest, consistent with Deb and Hunter, ${ }^{16}$ that epilepsy in itself is not a risk factor for psychiatric disorder.

Using regression, we found that greater seizure severity, greater seizure frequency and lesser loss of consciousness interacted with greater hyperactivity to predict PAS-ADD caseness. We might call this 'active epilepsy' in terms of seizure impact. Although explanatory power to identify cases was reduced by $20 \%$ when hyperactivity was excluded, both models allocated $90 \%$ of non-cases, implying that inactive epilepsy', as the inverse, was reliably associated with psychiatric stability. Confirming previous reports, ${ }^{35}$ type of seizure did not predict psychiatric state. Nevertheless, inclusion of loss of consciousness within the model suggests that this symptom contributes to stability. Perhaps seizures involving loss of consciousness are experienced as less distressing. Of course, loss of consciousness is a symptom of generalised seizures but the former appears to be a better explanatory variable. We conclude that better controlled epilepsy, along with seizures that have less social and cognitive impact, is less likely to be associated with psychiatric symptoms. Refractory epilepsy, associated with mental and behavioural impairment, is a risk factor for psychiatric disorder, but less reliably so.

\section{Behaviour}

Unexpectedly, our participants scored consistently lower than normative values (by $0.5 \mathrm{SD}$ ) on each of five dimensions of behavioural disturbance. This finding was not explained by differences in intellectual level, gender, or age. Perhaps normative samples were culturally different or had an overrepresentation of people with behavioural difficulties. Nevertheless, our data indicate that hyperactivity, lethargy, stereotyped behaviour, and inappropriate speech are not more prevalent in people with epilepsy. This conclusion is consistent with data from the majority of comparative studies; ${ }^{13} 193637$ only one having found higher levels (of irritability) on the ABC. ${ }^{20}$

For each of the five $\mathrm{ABC}$ scores, other $\mathrm{ABC}$ subscales or PAS-ADD caseness emerged as predictors. For example, almost $50 \%$ of variance in irritability was explained by hyperactivity scores alone, whereas only side effects and being ambulant remained after hyperactivity was removed, together explaining less than $10 \%$. Similarly, hyperactivity was explained largely by psychopathology, and after this was removed, explained variance dropped by $40 \%$ to $12.6 \%$, again leaving side effects and ambulation as the residual predictors. Only the lethargy subscale was largely unaffected by other behavioural measures. Greater intellectual and speech impairments with drug side effects explained almost $25 \%$ of variance, with stereotypy making a relatively modest contribution.

If we leave intercorrelation aside, behavioural outcomes (ABC) were most strongly related to non-epilepsy specific concerns such as intellectual, sensory, or motor function, compared with caseness (PAS-ADD), which was most strongly predicted by epilepsy specific concerns such as seizure severity and frequency, and the functional consequences of seizures. This suggests to us that seizure phenomena may represent an additional risk factor for psychiatric disorder, whereas some form of "disability index" contributes more to behaviour. Psychiatric disorder and behavioural problems may be correlated, but from our analysis they are not the same phenomenon, and should be separately addressed. Medication side effects, however, also contributed to the prediction of behaviour. We did not separately obtain side effect profiles for each AED, and informants may have been subject to attributional error; ${ }^{38}$ nevertheless, the possibility of deleterious behavioural effects is a matter of concern. Certainly, the literature references behavioural problems associated with AEDs and the amelioration of these with medication adjustment. ${ }^{39-42}$ Recent reviews also advocate evidence-based prescribing and balancing seizure and functional outcomes..$^{43} 44$

\section{Carer stress}

There are few published data on carer stress. We found 1 in 3 carers had clinically significant anxiety symptoms, and 1 in 10 had significant depressive symptoms, using conservative criteria on the HADS. Only the logistic regression model for anxiety yielded a significant predictor, in that seizure severity reliably identified non-cases, that is, where individuals have less severe seizures, their family carers are less at risk of anxiety. More than 1 in 2 had 'higher than usual stress' on the CSI. Here, only carer age (younger carers were more stressed) and greater side effects had explanatory power. This model correctly allocated $82 \%$ of those with normal stress, suggesting that life experience and few side effects may be protective against stress.

\section{Summary}

Some limitations in this study must be recognised. First, our prevalence figures are estimates and may not be generalisable. They lack reliable comparison for psychiatric disorder because normative data for the PAS-ADD have not been established, and published behavioural norms (ABC) do not include UK samples. Secondly, all our measures were self reports and represent screening data. Psychopathology in participants, and stress and anxiety/depression in carers may be overestimated relative to data derived from clinical assessment. Thirdly, our study design was correctional and causality should not be inferred from significant associations. The identification of 'predictors' of psychopathology should be understood within the general limitations of regression modelling. Nevertheless, there may be some useful implications. First, we suggest that epilepsy is a risk factor for psychopathology in only a minority of people with intellectual disability. Nevertheless, psychiatric disorder (mainly affective/neurotic) and behavioural problems should be assessed as separate phenomena because different factors appear to contribute to their presentation. Secondly, psychiatric disorder is least likely when seizures are well controlled, although loss of consciousness in seizures may be protective of emotional well-being (possibly a biological effect of seizures on mood, ${ }^{45} 46$ or patients being less aware of the seizure, or too tired to manifest distress). Thirdly, behavioural problems appear to be less epilepsy specific. Intellectual and sensory impairment are better predictors, although side effects of AEDs should be assessed because they may contribute to behaviour problems. Fourthly, the majority of family carers experience stress, and some may be symptomatic of anxiety disorder or depression. Effective epilepsy management may impact positively also on their mental health.

\section{Authors' affiliations}

C A Espie, J Watkins, J A Ryan, K Mantala, Department of Psychological Medicine, University of Glasgow, Academic Centre, Gartnavel Royal Hospital, 1055 Great Western Road, Glasgow G12 $\mathrm{OXH}, \mathrm{UK}$

L Curtice, Nuffield Centre for Community Care Studies, University of Glasgow, UK 
A Espie, Community Learning Disability Team, Old Johnstone Clinic, 1 Ludovic Square, Johnstone, UK

R Duncan, West of Scotland Regional Epilepsy Service, Southern General Hospital, Glasgow G51 4TF, UK

M J Brodie, Epilepsy Unit, Department of Medicine and Therapeutics, Western Infirmary, Glasgow, UK

M Sterrick, Lothian Learning Disabilities Service, Edinburgh, UK

Competing interest: This study was supported by grant K/RED/4/C357

from the Chief Scientist Office, Scottish Executive Health Department

\section{REFERENCES}

1 Richardson SA, Katz M, Koller H, et al. Some characteristics of a population of mentally retarded young adults in a British city. J Ment Defic Res 1979:23:275-87.

2 Goulden KJ, Shinnar S, Koller H, et al. Epilepsy in children with mental retardation: A cohort study. Epilepsia 1991;32:690-7.

3 Welsh Office. Welsh Health Survey. Cardiff: Welsh Office, 1995.

4 Hauser WA, Annegers JF, Kurland LT. Prevalence of epilepsy in Rochester, Minnesota. Epilepsia 1991;32:429-425.

5 Sander JW, Shorvon SD. Epidemiology of the epilepsies. J Neurol Neurosurg Psychiatry 1996;61:433-43.

6 Brodie MJ, Dichter MA. Antiepileptic drugs. N Engl J Medicine 1996:334:168-75.

7 International Association of the Scientific Study of Intellectual Disability (Working Group). Clinical guidelines for the management of epilepsy in adults with an intellectual disability. Seizure $2001 ; 10: 401-9$.

8 Hermann BP. The relevance of social factors to adjustment in epilepsy. In: Devinsky O, Theodore WH, eds. Epilepsy and behavior. New York: WileyLiss, 1991:23-36.

9 Jacoby A, Baker GA. Quality of life in epilepsy: Beyond seizure counts in assessment and treatment. Reading, England: Harwood Academic Publishers, 2000.

10 Espie CA, Watkins J, Duncan R, et al. Development and validation of the Glasgow Epilepsy Outcome Scale (GEOS): A new instrument for measuring concerns about epilepsy in people with mental retardation. Epilepsia 2001:42:1043-51.

11 McGrother CW, Hauck A, Burton PR, et al. More and better services for people with learning disabilities. J Public Health Med 1993;15:263-71.

12 Clinical Standards Advisory Group. Services for patients with epilepsy. London: CSAG 1999

13 Espie CA, Pashley AS, Bonham KG, et al. The mentally handicapped person with epilepsy: A comparative study investigating psychosocial functioning $J$ Ment Defic Res 1989;33:123-35.

14 Gillies JB, Espie CA, Montgomery JM. The social and behavioural functioning of people with mental handicaps attending Adult Training Centres: A comparison of those with and without epilepsy. Ment Handicap Res 1989;2:129-36.

15 Espie CA, Gillies JB, Montgomery JM. Antiepileptic polypharmacy, psychosocial behaviour and locus of control orientation among mentally handicapped adults living in the community. J Ment Defic Res 1990;34:351-60.

16 Deb S, Hunter D. Psychopathology of people with mental handicap and epilepsy. 1: Maladaptive behaviour. Br J Psychiatry 1991;159:822-6.

17 Deb S, Hunter D. Psychopathology of people with mental handicap and epilepsy. 2: Psychiatric illness. Br J Psychiatry 1991;159:826-30.

18 Deb S, Hunter D. Psychopathology of people with mental handicap and epilepsy. 3: Personality disorder. Br J Psychiatry 1991;159:830-4.

19 Matson J, Bamburg JW, Mayville EA, et al. Seizure disorders in people with intellectual disability: an analysis of differences in social functioning, adaptive functioning and maladaptive behaviours. J Intellect Disabil Res 1999;43:531-9.

20 Chung MC, Cassidy G. A preliminary report on the relationship between challenging behaviour and epilepsy in learning disability. Eur J Psychiatry $2001 ; 15: 23-32$.
21 Cohen J. A power primer. Psychol Bull 1991:112:155-9.

22 Sparrow SA, Balla DA, Cichetti DV. Vineland adaptive behaviour scale: expanded interview edition. Circle Pines, Minnesota: American Guidance, 1984

23 Baker GA, Jacoby A, Smith DF, et al. Development of a novel scale to assess quality of life as part of a further refinement of a $Q O L$ model for epilepsy. Epilepsia 1994;35:591-6.

24 Espie CA, Paul A. Epilepsy and Learning Disabilities. In: Cull C, Goldstein LH, eds. The clinical psychologists handbook of epilepsy. London: Routledge, 1997:184-202.

25 Moss SC, Ibbotson B, Prosser $H$, et al. Validity of the PAS-ADD for detecting psychiatric symptoms in adults with learning disability (mental retardation). Soc Psychiatry Psychiatr Epidemiol 1997;32:344-54.

26 Moss SC, Prosser H, Costello H, et al. The psychiatric assessment schedule for adults with developmental disability: PAS-ADD checklist. Manchester: University of Manchester, Hester Adrian Research Centre, 1997.

27 Aman MG, Singh NN, Stewart AW, et al. The Aberrant Behavior Checklist: A behavior rating scale for the assessment of treatment effects. Am J Ment Defic 1985;89:485-91

28 Aman MG, Singh NN. Aberrant behaviours checklist-community: supplementary manual. New York: Slosson Educational Publications, 1994.

29 Espie CA, Kerr M, Paul A, et al. Learning disability and epilepsy. 2: A review of available outcome measures and position statement on development priorities. Seizure 1997;6:337-50.

30 Newton JT, Sturmey P. The Aberrant Behaviour Checklist: a British replication and extension of its psychometric properties. J Ment Defic Res 1988;32:87-92.

31 Zigmond AS, Snaith RP. The Hospital Anxiety and Depression Scale. Acta Psychiatr Scand 1983:67:361-70.

32 Robinson BC. Validation of a care giver strain index. J Gerontol 1983;38:344-8.

33 Roy A, Martin DM, Wells MB. Health gain through screening-mental health: Developing primary health care services for people with an intellectual disability. J Intellect Dev Disabil 1997;22:227-39.

34 Hosmer DW, Lesmehow S. Applied logistic regression. New York: Wiley, 1989.

35 Deb S. Electrophysiological correlates of psychopathology in individuals with mental retardation and epilepsy. J Intellect Disabil Res 1995;39:129-35.

36 Collacott RA. Epilepsy, dementia and adaptive behaviour in Down's syndrome. J Intellect Disabil Res 1993;37:153-60.

37 Prasher VP. Epilepsy and asociated effects on adaptive behaviour in adults with Down syndrome. Seizure 1995;4:53-6.

38 Deb S, Hunter D. The effect of anticonvulsant medication on the psychopathology of adults with a mental handicap and epilepsy. Human Psychopharmacol 1992;7:129-34.

39 Mirza WU, Credeur L, Penry JK. Results of antiepileptic drug reduction in patients with multiple handicaps and epilepsy. Drug Invest 1993;5:320-6.

40 Kalachnik JE, Hanzel TE, Harder SR, Bauernfeind JD, Engstrom EA. Antiepileptic drug behavioral side effects in individuals with mental retardation and the use of behavioral measurement techniques. Ment Retard 1995;33:374-82.

41 Beran RG, Gibson RJ. Aggressive behaviour in intellectually challenged patients with epilepsy treated with lamotrigine. Epilepsia 1998:39:280-2

42 Ettinger AB, Weisbrot DM, Saracco J, et al. Positive and negative psychotropic effects of lamotringine in patients with epilepsy and mental retardation. Epilepsia 1998:39:874-7.

43 Brown S. Treatment of patients with epilepsy and severe and profound learning disability. Eur J Neurol 1996;3:35-7.

44 Santosh PJ, Baird G. Psychopharmacotherapy in children and adults with intellectual disability. Lancet 1999;354:231-40.

45 Wolf $\mathbf{P}$. The clinical syndrome of forced normalisation. Br J Psychiatry 1985; 146:272-6.

46 Reid S, Mothersill I. Forced normalisation: the clinical neurologist's review. In: Trimble M, Schmitz, eds. Forced normalisation and alternative psychoses of epilepsy. Brighton: Wrightson Biomedical, 1998:77-84. 